\title{
Pengembangan Sistem Informasi Geografis Lokasi Bencana Di Perkotaan Dan Pencarian Jalur Evakuasi Dengan Algoritma A*
}

\author{
Erfan Rohadi \\ Program Studi Teknik Informatika, \\ Jurusan Teknologi Informasi, \\ Politeknik Negeri Malang \\ Malang, Jawa Timur Indonesia \\ erfanr@polinema.ac.id
}

\author{
Siti Muzdalifatus Sa'adah \\ Program Studi Teknik Informatika, \\ Jurusan Teknologi Informasi, \\ Politeknik Negeri Malang \\ Malang, Jawa Timur Indonesia \\ sitimuzdalifatus@gmail.com
}

\author{
Yan Watequlis Syaifudin \\ Program Studi Teknik Informatika, \\ Jurusan Teknologi Informasi, \\ Politeknik Negeri Malang \\ Malang, Jawa Timur Indonesia \\ yan@polinema.ac.id
}

\begin{abstract}
Climate change or global warming, many cause disasters. Where in each region has the potential for disaster, including in the city of Malang. The types of disasters that are prone to occur in the city of Malang include floods, landslides and fires. Evacuation must occur immediately to the nearest evacuation point. To get to an evacuation point, the Rapid Disaster Response Team (TRC) of the Regional Disaster Management Agency (BPBD) can encounter obstacles, namely in determining the nearest evacuation point along with the shortest path. Another obstacle is the existence of several locations of traffic jams on certain roads. The density of the traffic flow can hamper the evacuation process by the BPBD TRC and the community to go to the disaster evacuation site. In this study the authors used the A * (A Star) Algorithm. This application is expected to help the Rapid Disaster Response Team (TRC) of the City of Malang Disaster Management Agency (BPBD) to find out the nearest evacuation point along with which route should be passed, so that the evacuation process can be carried out quickly so as not to cause greater losses. Based on the results of tests that have been carried out in the application of Algorithm $A *$ to search for evacuation routes, it has an accuracy of $100 \%$, which means that applications developed can be used to determine disaster evacuation routes.
\end{abstract}

Keywords-Geographic Information Systems, Disasters, Evacuation Paths, Algorithm A *

Abstrak - Perubahan iklim atau pemanasan global, banyak mengakibatkan bencana. Dimana pada masing-masing wilayah memiliki potensi bencana, termasuk di wilayah Kota Malang. Jenis bencana yang rawan terjadi di wilayah Kota Malang meliputi banjir, tanah longsor, dan kebakaran. Terjadinya bencana harus segera dilakukan evakuasi ke titik evakuasi terdekat. Untuk menuju ke suatu titik evakuasi, Tim Reaksi Cepat (TRC) Badan Penanggulangan Bencana Daerah (BPBD) dapat menemui kendala, yaitu dalam menentukan titik evakuasi yang terdekat beserta jalur terpendeknya. Kendala lainnya yaitu adanya beberapa titik lokasi kemacetan di ruas jalan tertentu. Kepadatan arus lalu lintas dapat menghambat proses evakuasi oleh TRC BPBD maupun masyarakat untuk menuju ke tempat evakuasi bencana. Dalam penelitian ini penulis menggunakan Algoritma A* (A Star) . Aplikasi ini diharapkan dapat membantu Tim Reaksi Cepat (TRC) Badan Penanggulangan Bencana Daerah (BPBD) Kota Malang untuk mengetahui titik evakuasi terdekat beserta jalur mana yang harus dilewati, sehingga proses evakuasi dapat dilakukan dengan cepat agar tidak menimbulkan kerugian yang lebih besar. Berdasarkan hasil uji yang telah dilakukan dalam penerapan Algoritma $A^{*}$ untuk pencarian jalur evakuasi, mempunyai akurasi sebesar $100 \%$, yang berarti aplikasi yang dikembangkan dapat digunakan untuk menentukan jalur evakuasi bencana.

Kata Kunci-- Sistem Informasi Geografis, Bencana, Jalur Evakuasi, Algoritma A*

\section{PENDAHULUAN}

Perubahan iklim atau pemanasan global, banyak mengakibatkan bencana. Dimana pada masing-masing wilayah memiliki potensi bencana, termasuk di wilayah Kota Malang. Jenis bencana yang rawan terjadi di wilayah Kota Malang meliputi banjir, tanah longsor, dan kebakaran.

Terjadinya suatu bencana dapat menimbulkan korban jiwa, kerugian material dan kerusakan lingkungan. Sehingga Tim Reaksi Cepat (TRC) Badan Penanggulangan Bencana Daerah (BPBD) Kota Malang harus segera melakukan tindakan evakuasi maupun penanganan dengan cepat di lokasi kejadian bencana untuk meminimalisir dampak bencana yang ditimbulkan. Ketika terjadi suatu bencana, Tim Reaksi Cepat BPBD maupun masyarakat terkait, harus segera melakukan evakuasi ke titik evakuasi terdekat. Dalam melakukan upaya evakuasi, TRC BPBD berkemungkinan dapat menemui kendala, yaitu dalam menentukan titik evakuasi yang terdekat beserta jalur terpendeknya. Kendala lainnya yaitu adanya beberapa titik lokasi kemacetan di ruas jalan tertentu, mengingat Malang adalah salah satu kota besar dan memiliki arus lalu lintas yang cukup padat. Kepadatan arus lalu lintas dapat menghambat proses evakuasi oleh TRC BPBD maupun masyarakat untuk menuju ke tempat evakuasi bencana.

Algoritma A* (A-Star) merupakan metode pencarian yang membuang langkah-langkah yang tidak perlu dengan pertimbangan bahwa langkah-langkah yang dibuang sudah pasti merupakan langkah yang tidak akan mencapai solusi yang diinginkan [1]. Selain itu Algoritma A-Star merupakan gabungan antara algoritma pencarian Uniform Cost dan GreedyBest First. Algoritma Uniform cost digunakan untuk mencari biaya yang paling rendah untuk dimulai dari titik awal hingga akhir,sedangkan algoritma Greedy-best first digunakan untuk memberikan estimasi biaya dari titik awal hingga akhir dengan menggunakan fungsi heuristik. Salah satu implementasi dari algoritma A-Star digunakan untuk 
mencari jalur tercepat [2]. Algoritma A* dapat digunakan untuk penentuan rute terpendek pendistribusian barang [3]. Pada penelitian ini Algoritma $\mathrm{A}^{*}$ digunakan untuk menentukan jalur evakuasi jika terjadi bencana di wilayah perkotaan. Studi kasus wilayah perkotaan yang digunakan pada penelitian ini adalah Kota Malang, Jawa Timur.

Berawal dari permasalahan tersebut, maka perlu dikembangkan sebuah aplikasi Sistem Informasi Geografis Lokasi Bencana di Kota Malang dan Pencarian Jalur Evakuasi Dengan Algoritma A*. Algoritma A* merupakan salah satu algoritma yang termasuk dalam kategori metode pencarian yang memiliki informasi (informed search method). Algoritma ini sangat baik sebagai solusi proses pathfinding. Algoritma ini mencari jarak rute tercepat yang akan ditempuh suatu titik awal (starting point) sampai ke titik tujuan [4]. Algoritma A* menggunakan estimasi jarak terdekat untuk mencapai tujuan (goal) dan memiliki nilai heuristik yang digunakan sebagai dasar pertimbangan. Heuristik adalah kriteria, metoda, atau prinsip-prinsip untuk menentukan pilihan sejumlah alternatif untuk mencapai sasaran dengan efektif. Dalam sistem yang dibangun, faktor heuristik yang dipertimbangkan yaitu panjang lintasan dan adanya titik kepadatan lalu lintas.

Penelitian ini bertujuan untuk membangun sistem informasi geografis lokasi bencana di wilayah perkotaan dan penentuan jalur evakuasi menggunakan algoritma $A^{*}$. Penggunaan aplikasi ini diharapkan dapat membantu Tim Reaksi Cepat (TRC) Badan Penanggulangan Bencana Daerah (BPBD) Kota Malang dalam mengetahui titik evakuasi terdekat beserta jalur mana yang harus dilewati, sehingga proses evakuasi dapat dilakukan dengan cepat agar tidak menimbulkan kerugian yang lebih besar.

\section{SISTEM INFORMASI GEOGRAFIS}

Sistem Informasi Geografis (SIG) atau Geographic Information System (GIS) adalah sebuah sistem yang didesain untuk menangkap, menyimpan, memanipulasi, menganalisa, mengatur dan menampilkan seluruh jenis data geografis. Sistem ini diimplementasikan dengan menggunakan perangkat keras dan perangkat lunak komputer yang berfungsi untuk : (a) akusisi dan verifikasi data, (b) kompilasi data, (c) penyimpanan data, (d) perubahan dan atau update data, (e) manajamen dan pertukaran data, (f) manipulasi data, (g) pemanggilan dan presentasi data, dan (h) analisis data.

SIG merupakan salah satu sistem yang kompleks, dan pada umumnya juga (selain yang stand-alone) terintegrasi dengan lingkungan sistem komputer lainnya ditingkat fungsional dan jaringan (network). SIG sebagai sistem terdiri dari beberapa komponen antara lain: perangkat keras, perangkat lunak, data dan informasi geografi, manajemen [5].

\section{ALGORITMA A*}

Algoritma $A^{*}$ (A Star) adalah algoritma pencarian yang merupakan pengembangan dari algoritma Best First Search (BFS). Seperti halnya pada BFS, untuk menemukan solusi, A* juga 'dituntun' oleh fungsi heuristik, yang menentukan urutan titik mana yang akan dikunjungi terlebih dahulu. Heuristik merupakan penilai yang memberi harga (cost) pada tiap verteks yang memandu $\mathrm{A}^{*}$ mendapatkan solusi yang diinginkan.

Algoritma ini pertama kali diperkenalkan pada 1968 oleh Peter Hart, Nils Nilsson, dan Bertram Raphael Dalam tulisan mereka, algoritma ini dinamakan algoritma A. Dengan penggunaan fungsi heuristik yang tepat pada algoritma ini yang dapat memberikan hasil yang optimal, maka algoritma ini pun disebut $A^{*}$.

Algoritma ini memeriksa node dengan menggabungkan $g(n)$, yaitu cost yang dibutuhkan untuk mencapai sebuah node dan $h(n)$ yaitu cost yang didapat dari node ke tujuan [6]. Sehingga dapat dirumuskan sebagai:

Keterangan:

$$
f(n)=g(n)+h(n) \quad \ldots(2.1)
$$

$f(n)$ : estimasi total biaya (cost) sebuah jalur (path) dari node awal ke node tujuan (goal) melalui node $n$.

$g(n)$ : biaya (cost) yang dibutuhkan oleh sebuah jalur (path) untuk mencapai node $\mathrm{n}$ dari node awal.

$h(n)$ : estimasi biaya (cost) sebuah jalur (path).

\section{GOOGLE MAPS API}

API (Application Programming Interface) adalah fungsifungsi pemrograman yang disediakan oleh aplikasi atau layanan agar layanan tersebut bisa diintegrasikan dengan aplikasi yang dibuat. Google Maps API adalah fungsi-fungsi pemrograman yang disediakan oleh Google Maps agar Google Maps bisa diintegrasikan ke dalam aplikasi yang sedang dibuat.

Google Maps API sendiri menyediakan fungsi yang banyak, berikut ini adalah pembagiannya :

1. Google Maps JavaScript API v3, ini adalah Google Maps API yang tersedia dalam bahasa JavaScript.

2. Google Maps API Web Service, layanan Google Maps API untuk fungsi lanjutan seperti direction, Geocoding, Distance Matrix API dan Elevation API.

3. Google Place API, ini adalah API wajib yang harus dikuasai untuk membuat aplikasi Location Based Service.

Semua aplikasi yang membutuhkan layanan peta dapat dibuat. Aplikasi tidak terbatas pada website, namun juga bisa aplikasi desktop ataupun aplikasi di smartphone bahkan aplikasi di embedded system misalkan aplikasi navigasi di mobil[11].

\section{A. Analisis Sistem}

\section{HASIL PENELITIAN}

Aplikasi Sistem Informasi Geografis Lokasi Bencana yang disertai pencarian jalur evakuasi terpendek ini merupakan aplikasi yang dibuat dengan tujuan untuk mempermudah masyarakat Kota Malang dalam melaporkan terjadinya suatu bencana, baik banjir, kebakaran maupun tanah longsor, serta membantu pihak BPBD maupun masyarakat dalam pencarian jalur evakuasi terpendek. Pada sistem ini terdapat dua hak akses yaitu admin dan user. Sistem akan melibatkan user yang memanfaatkan perangkat mobile. Untuk menggunakan aplikasi, user harus terlebih dahulu terhubung dengan jaringan internet agar dapat menggunakan geolocation untuk mendeteksi koordinat posisi pengguna terkini, sebagai inputan posisi awal dalam melakukan pencarian jalur evakuasi maupun untuk posting informasi bencana. Sistem akan membaca database dan 
membaca peta dari Google Maps. Sedangkan, melalui perangkat komputer, administrator dapat mengelola sistem pada server aplikasi melalui website yaitu mengelola data bencana yang selanjutnya akan dapat ditampilkan disertai peta lokasi bencana maupun peta evakuasi. Data-data tersebut juga dapat dilihat oleh pengguna aplikasi lainnya yang sedang terhubung melalui internet.

\section{B. Perancangan Sistem}

Dalam perancangan Aplikasi Sistem Informasi Geografis Lokasi Bencana di Kota Malang dan Pencarian Jalur Evakuasi dapat menggunakan berbagai model untuk menggambarkan alur proses aplikasi.

Use case adalah rangkaian atau uraian kelompok yang saling terkait dan membentuk sistem secara teratur yang dilakukan atau diawasi oleh sebuah aktor. Sehingga customer atau pengguna sistem paham dan mengerti mengenai kegunaan sistem yang akan dibangun.

Pada Gambar 2 menunjukkan bahwa dalam diagram use case terdapat dua aktor, yaitu admin dan user. Admin atau administrator yang dimaksudkan disini adalah orang yang memiliki wewenang mengelola data, yaitu menambahkan, menghapus, dan mengubah data bencana, data titik evakuasi, data lokasi rawan bencana, data kecamatan, dan laporan bencana di Kota Malang, yaitu admin dari pihak Badan Penanggulangan Bencana Daerah (BPBD) Kota Malang. Sedangkan, user merupakan orang yang mengakses atau menjalankan aplikasi, yaitu masyarakat umum di Kota Malang dan TRC BPBD.

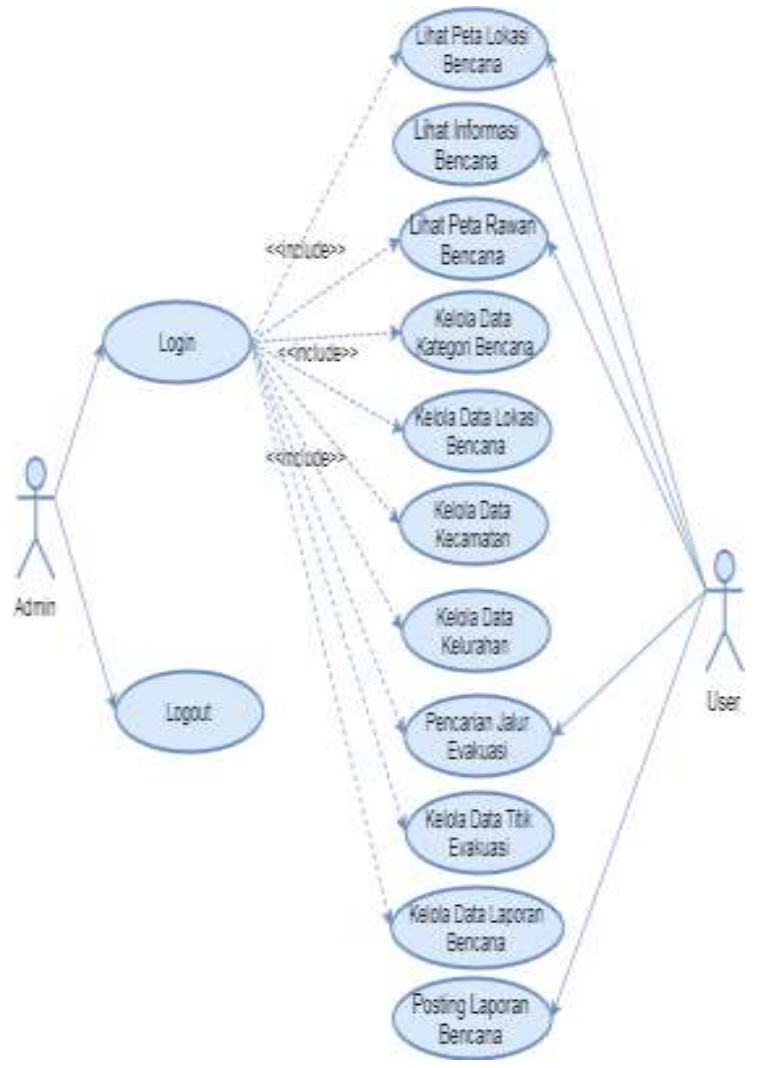

Gambar 2 Use Case Diagram

\section{Pengolahan Data}

Dalam pengolahan data yang dilakukan pada penelitian ini, data yang telah diperoleh akan di jadikan sebagai lokasi tujuan dan rute jalan yang dilalui. Dalam perutean yang dilakukan dalam penelitian ini menggunakan Algoritma A* (A Star). Gambar 1 merupakan flowchart pencarian titik evakuasi terdekat dengan jalur terpendek menggunakan Algoritma A*.

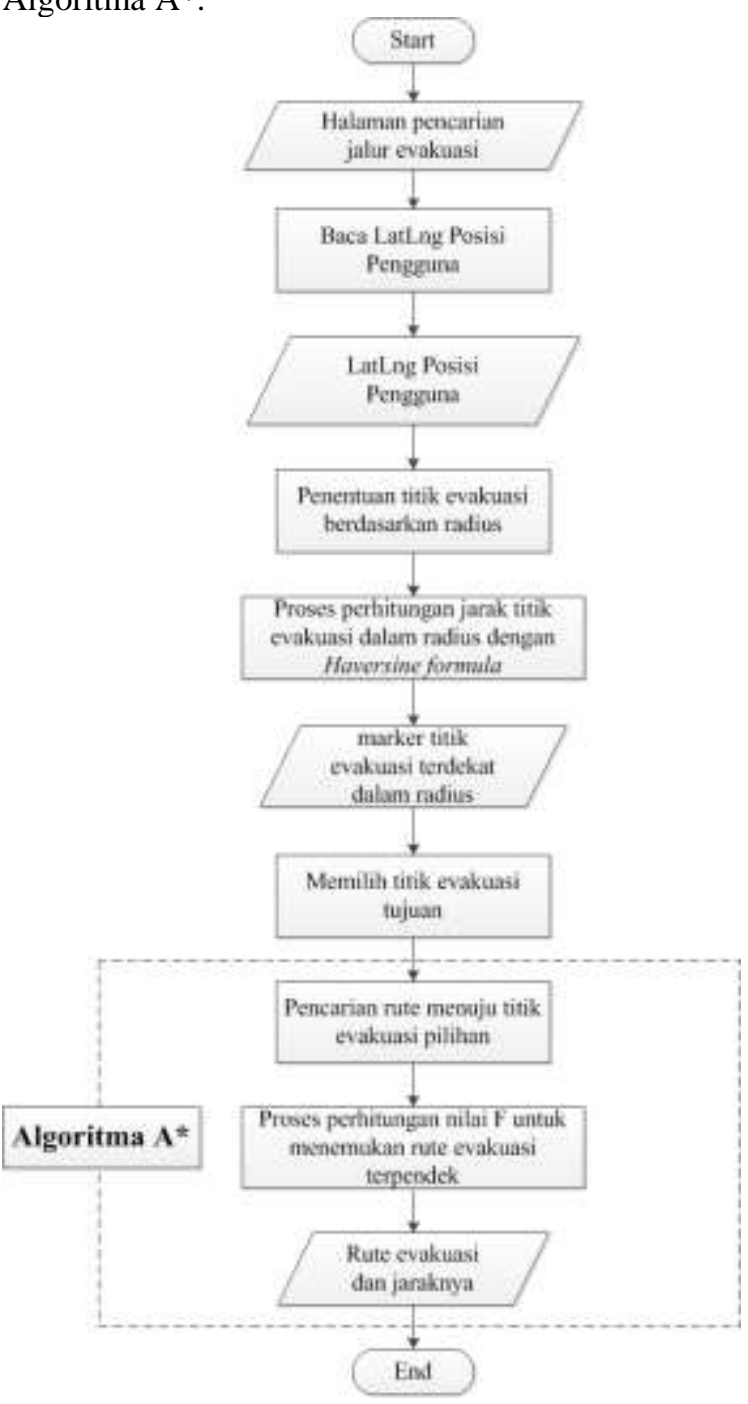

Gambar 1 Flowchart pencarian jalur evakuasi

Sistem ini menggunakan proritas pada vertex graf dengan kondisi sebagai berikut:

TABLE I. TABEL PRIORITAS

\begin{tabular}{|l|l|}
\hline \multirow{2}{*}{ Prioritas } & Keterangan \\
\hline 0,30 & Ruas jalan raya dengan LOS $=\mathrm{A}$ \\
\hline 0,50 & Ruas jalan raya dengan LOS $=\mathrm{B}$ \\
\hline 0,75 & Ruas jalan raya dengan LOS $=\mathrm{C}$ \\
\hline 0,90 & Ruas jalan raya dengan $\mathrm{LOS}=\mathrm{D}$ \\
\hline 1,00 & Ruas jalan raya dengan $\mathrm{LOS}=\mathrm{E}$ \\
\hline 1,20 & Ruas jalan raya dengan $\mathrm{LOS}=\mathrm{F}$ \\
\hline 0,30 & Ruas jalan raya dengan LOS $=\mathrm{A}$ \\
\hline
\end{tabular}

Perhitungan bobot dilakukan pada saat perhitungan nilai $g(x)$ sehingga rumusnya adalah sebagai berikut. 


$$
\begin{aligned}
& g_{\text {total }}(x)=g_{\text {antara } 2 \text { node }}(x) \times \text { prioritas } \\
& =g_{\text {terlewati }}(x)+h(x)
\end{aligned}
$$

\section{Implementasi}

Pembuatan tampilan web merupakan proses penghubungan sistem yang telah dirancang kemudian diterapkan dalam program. Dalam pembuatan aplikasi ini penulis menggunakan bahasa pemrograman Javascript dan PHP dengan framework CodeIgniter. Berikut merupakan implementasi dari Sistem Informasi Geografis Lokasi Bencana di Kota Malang dan Pencarian Jalur Evakuasi.

\subsubsection{Halaman Beranda}

Gambar 3 merupakan screenshot halaman beranda. Pada halaman ini terdapat beberapa menu antara lain: menu beranda, peta rawan bencana, peta evakuasi bencana, jenis bencana, lokasi rawan bencana, kecamatan, kelurahan, titik evakuasi, kategori titik evakuasi, dan laporan bencana. Pada halaman ini admin juga dapat melihat peta bencana yang sedang terjadi di Kota Malang. Setiap laporan bencana akan ditunjukkan pada peta berupa marker, sesuai dengan posisi dari user yang melaporkan bencana tersebut.
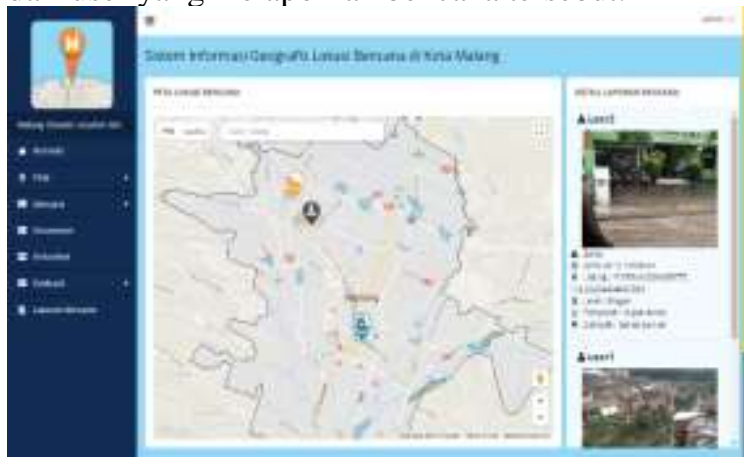

Gambar 3 Halaman beranda

\subsubsection{Pencarian Jalur Evakuasi Bencana}

Gambar 4 merupakan screenshot halaman peta evakuasi bencana. Pada halaman ini pengguna dapat melihat peta persebaran titik evakuasi bencana yang ada di Kota Malang. Untuk melalukan pencarian, pengguna harus memilih radius titik evakuasi tujuan terlebih dahulu. Peta akan menampilkan lokasi berdasarkan radius dari posisi user yang telah dipilih.

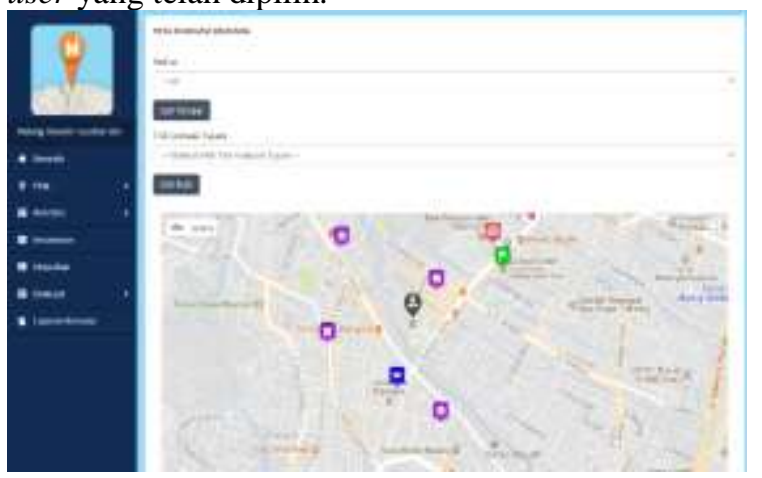

Gambar 4 Halaman peta evakuasi bencana

Titik evakuasi yang berada dalam radius tersebut akan ditampilkan pada dropdown berdasarkan urutan dari radius terdekat. Kemudian pengguna harus memilih salah satu titik evakuasi tujuan pada dropdown. Apabila tombol cari rute dipilih, sistem akan menampilkan graph disertai pilihan/alternatif rute ke tempat tujuan, seperti yang ditampilkan pada Gambar 5.
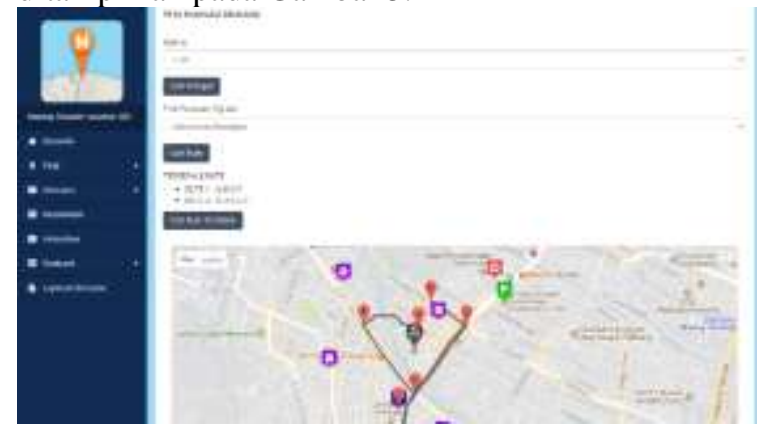

Gambar 5 Graph rute evakuasi

Titik-titik pada graph yang ditampilkan tersebut merupakan rute yang akan dihitung menggunakan algoritma A* untuk menemukan jalur evakuasi terpendek. Hasil dari pencarian jalur evakuasi ini adalah rute yang memiliki nilai f paling rendah. Hasilnya ditampilkan seperti pada Gambar 6. Sistem juga menampilkan jarak yang ditempuh dalam satuan kilometer.

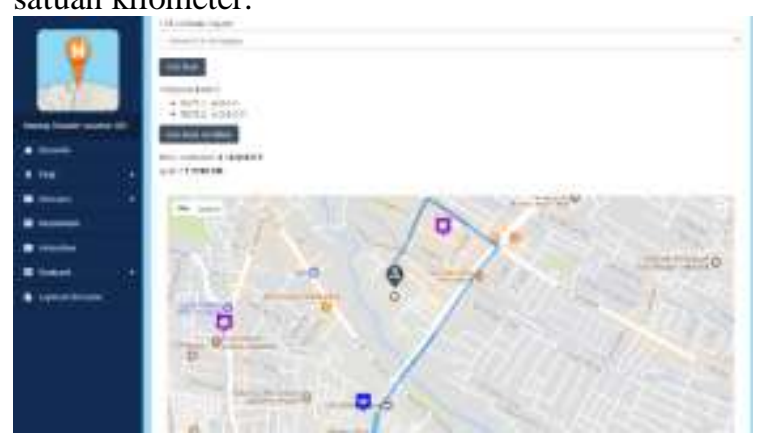

Gambar 6 Hasil pencarian jalur evakuasi

\subsubsection{Halaman Laporan Bencana}

Gambar 7 merupakan screenshot halaman laporan bencana. Pada halaman ini terdapat dua tabel laporan bencana yaitu tabel yang berisi laporan bencana masuk (belum dikonfirmasi) dan tabel laporan bencana yang sudah dikonfirmasi.

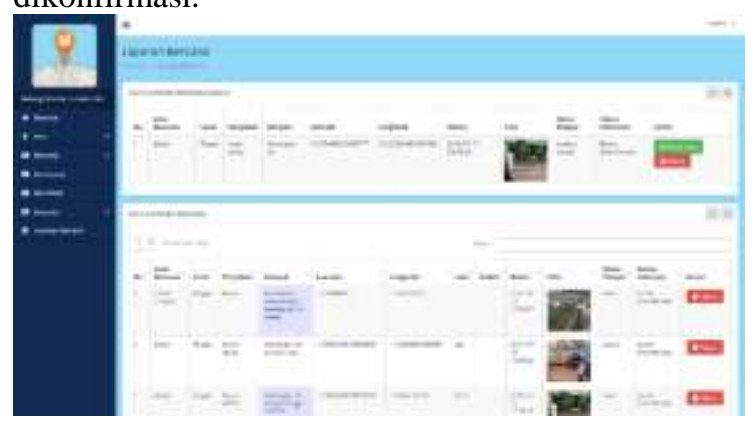

Gambar 7 Halaman laporan bencana

4. Pengujian dan Pembahasan

Pada tahap ini terdapat 2 jenis pengujian yang akan ditampilkan hasilnya yaitu fungsional dan pengujian validasi.

4.1 Pengujian Fungsional

Pada pengujian sistem ini, terdapat beberapa parameter yang digunakan untuk memastikan bahwa sistem telah berjalan sesuai dengan rancangan, diantaranya berjalannya seluruh fungsi dari setiap fitur yang ada pada sistem, sistem 
dapat memunculkan posisi lokasi bencana, serta stabilitas penerimaan dari database ke sistem.

\subsection{Pengujian Akurasi Sistem}

Uji coba akurasi sistem yang dilakukan adalah dengan membandingkan hasil perhitungan manual pada Excel dengan hasil perhitungan sistem. Data yang digunakan untuk pengujian adalah 10 data sample dari data titik evakuasi yang ada. Titik awal yang digunakan berada di Politeknik Negeri Malang berdasarkan dari koordinat lokasi GPS/Geolocation penulis. Uji coba dilakukan untuk mengetahui tingkat akurasi algoritma $\mathrm{A}^{*}$.

Tabel 2 Hasil pengujian akurasi sistem

\begin{tabular}{|c|c|c|c|}
\hline No & Nama & $\begin{array}{c}\text { Hasil } \\
\text { Manual } \\
\end{array}$ & $\begin{array}{c}\text { Hasil } \\
\text { Sistem } \\
\end{array}$ \\
\hline 1 & $\begin{array}{l}\text { Universitas } \\
\text { Brawijaya }\end{array}$ & 1754.2 & 1754.4 \\
\hline 2 & $\begin{array}{c}\text { Universitas } \\
\text { Muhammadiyah } \\
\text { Malang }\end{array}$ & 3769.2 & 3807.3 \\
\hline 3 & $\begin{array}{c}\text { Taman Krida } \\
\text { Budaya }\end{array}$ & 1166 & 1166 \\
\hline 4 & $\begin{array}{c}\text { Sekolah Tinggi } \\
\text { Ilmu Administrasi } \\
\text { Malang }\end{array}$ & 2350.4 & 2388.6 \\
\hline 5 & $\begin{array}{c}\text { Universitas Islam } \\
\text { Malang }\end{array}$ & 2002.6 & 2003 \\
\hline 6 & $\begin{array}{c}\text { Universitas } \\
\text { Gajayana }\end{array}$ & 2399.5 & 2399.7 \\
\hline 7 & $\begin{array}{c}\text { Rumah Sakit } \\
\text { Islam UNISMA }\end{array}$ & 1597.8 & 1598.2 \\
\hline 8 & Lapangan Rampal & 5763 & 5763.4 \\
\hline 9 & $\begin{array}{c}\text { STIE } \\
\text { Malangkucecwara } \\
\end{array}$ & 3633.23 & 3633.4 \\
\hline 10 & $\begin{array}{l}\text { Rumah Sakit } \\
\text { Persada }\end{array}$ & 5559.9 & 5560.1 \\
\hline
\end{tabular}

Dengan menggunakan toleransi maksimal $50 \mathrm{~m}$, dari Tabel 2 di dapatkan 10 data yang sesuai dari 10 data sample. Dengan hasil perbandingan tersebut maka didapatkan hasil $100 \%$. Hasil ini sejalan dengan penelitian [7][8][9][10] dimana algoritma $\mathrm{A}^{*}$ dapat digunakan untuk menentukan rute terpendek pencarina jalur evakuasi bencana di wilayah perkotaan.

\subsection{Hasil Uji Coba Terhadap Pengguna}

Untuk menguji sistem dari segi tampilan, friendly user, kehandalan dan manfaat dari aplikasi yang dibuat, telah dilakukan penyebaran kuesioner kepada 20 responden, dengan pernyataan antara lain:

1. Aplikasi memiliki tampilan yang user friendly.

2. Aplikasi mudah dioperasikan.

3. Aplikasi memudahkan pengguna dalam melaporkan

4. Aplikasi membantu dalam menemukan titik evakuasi terdekat.

5. Aplikasi bermanfaat bagi pengguna.

Responden yang dimaksud adalah masyarakat umum di Kota Malang. Pendapat dari responden tersebut ditampilkan pada Tabel 3 .

\begin{tabular}{|c|c|c|c|c|c|}
\hline \multirow{2}{*}{ No. } & \multicolumn{5}{|c|}{ Skala Jawaban } \\
\cline { 2 - 6 } & $\mathbf{1}$ & $\mathbf{2}$ & $\mathbf{3}$ & $\mathbf{4}$ & $\mathbf{5}$ \\
\hline 1. & 0 & 0 & 0 & 13 & 7 \\
\hline 2. & 0 & 0 & 2 & 15 & 3 \\
\hline 3. & 0 & 0 & 3 & 15 & 2 \\
\hline 4. & 0 & 1 & 10 & 7 & 2 \\
\hline 5. & 0 & 0 & 6 & 13 & 1 \\
\hline
\end{tabular}

Prosentasi hasil kuesioner pada Tabel 3 ditunjukkan pada Grafik 1.

Grafik 1 Prosentase Hasil Kuesioner

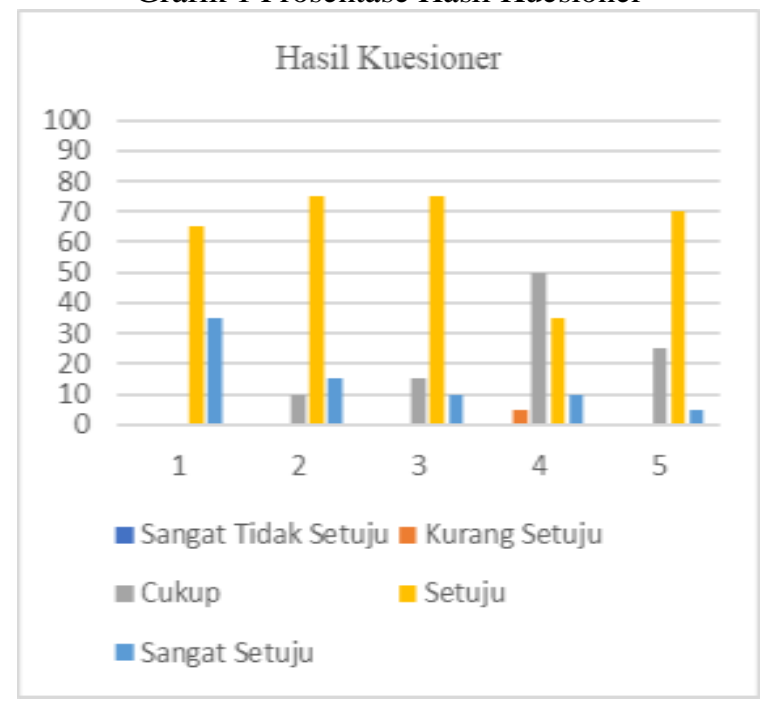

Grafik 1 menunjukkan $65 \%$ responden setuju dan 35\% responden sangat setuju bahwa aplikasi memiliki tampilan yang user friendly. $75 \%$ responden setuju dan $15 \%$ responden sangat setuju bahwa aplikasi mudah dioperasikan. Sedangkan $75 \%$ responden setuju dan $10 \%$ responden sangat setuju bahwa aplikasi memudahkan pengguna dalam melaporkan kejadian bencana, 35\% responden setuju dan $10 \%$ responden sangat setuju bahwa aplikasi membantu dalam menemukan titik evakuasi terdekat. Serta $75 \%$ responden berpendapat bahwa aplikasi ini bermanfaat.

\section{KESIMPULAN}

Berdasarkan hasil penelitian yang telah dilakukan oleh penulis mengenai Pengembangan Sistem Informasi Geografis Lokasi Bencana di Kota Malang dan Pencarian Jalur Evakuasi dengan Algoritma $\mathrm{A}^{*}$, dapat disimpulkan user dapat melakukan pencarian titik evakuasi terdekat dengan menggunakan aplikasi informasi pencarian jalur evakuasi untuk menemukan titik evakuasi terdekat di Kota Malang ini sesuai dengan lokasi user berada pada saat pengujian tersebut. Berdasarkan hasil uji yang telah dilakukan dalam penerapan Algoritma A* untuk pencarian jalur evakuasi, hasil akurasi yang didapatkan adalah sebesar $100 \%$. Saran untuk pengembangan lebih lanjut dari penelitian skripsi ini adalah menerapkan algoritma atau metode lain untuk dapat meningkatkan nilai akurasi yang lebih baik dan memperluas ruang lingkup wilayah, bukan hanya di Kota Malang, tetapi meliputi Malang Raya. 


\section{REFERENSI}

[1] M. Yamin, "Aplikasi Pencarian Jalur Terpendek Pada Rumah Sakit Umum Bahteramas Menggunakan Algoritma A*," Jurnal Informatika, vol. 9, no. 2, pp. 1065-1078, 2015.

[2] R. A. Nugraeni and R. Mulyono, "Penerapan Algoritma A* Dalam Penyelesaian Rute Terpendek Pendistribusian Barang," UNNES Journal of Mathematics, vol. 4, no. 1, pp. 7-12, 2015.

[3] I. Ahmad and W. Widodo, "Penerapan Algoritma A Star (A*) pada Game Petualangan Labirin Berbasis Android," Khazanah Informatika, vol. 3, no. 2, pp. 57-63, 2017.

[4] D. Hermanto and S. Dermawan, "Penerapan Algoritma A-Star Sebagai Pencari Rute Terpendek pada Robot Hexapod," Jurnal Nasional Teknik Elektro, vol. 7, no. 2, pp. 122-129, 2018.

[5] E. Irwansyah, Sistem Informasi Geografis: Prinsip Dasar dan Pengembangan Aplikasi, Yogyakarta: Digibooks, 2013.

[6] I. B. G. W. A. Dalem, "PENERAPAN ALGORITMA A* (STAR) MENGGUNAKAN GRAPH UNTUK MENGHITUNG JARAK TERPENDEK," Jurnal Resistor, vol. 1, no. 1, pp. 41-47, 2018.

[7] I. A. Dewi, A. Nana and S. D. Aryanti, "Algoritma A* Dalam Peletakan Pola Pakaian Pada Kain," Jurnal Infotel, vol. 9, no. 4, pp. 443-453, 2017

[8] S. Purnama, D. A. Megawaty and Y. Fernando, "PENERAPAN ALGORITMA A STAR (A*) UNTUK PENENTUAN JARAK TERDEKAT WISATA KULINER DI KOTA BANDARLAMPUNG," Jurnal Teknoinfo, vol. 12, no. 1, pp. 28-32, 2018.

[9] Y. Syukriyah, Falahah and H. Solihin, "PENERAPAN
ALGORITMA A* (STAR) UNTUK MENCARI RUTE TERCEPAT DENGAN HAMBATAN," in Seminar Nasional Telekomunikasi dan Informatika (SELISIK 2016), Bandung, 2016.

[10] A. I. S. Pane, PENCARIAN RUTE TERDEKAT LOKASI KEBAKARAN DI KOTA MEDAN MENGGUNAKAN ALGORITMA A STAR (A*), Medan: Universitas Sumatera Utara, 2018.

[11] G. Svennerberg, Beginning Google Maps API 3, New York: Apress, 2010. 